\title{
Potential Involvement of Cell Cycle-Related Genes in the Arrest of Stamen Development of Female Flowers During Sex Expression in Cucumber (Cucumis sativus L.)
}

\author{
Seiji Yamasaki, Ryusei Yamakuchi, Saori YamanaKa and Kazuto Manabe \\ Laboratory of Plant Physiology, Department of Science Education, Faculty of Education, University of Teacher \\ Education Fukuoka, 1-1 Akamabunkyomachi, Munakata, Fukuoka 811-4192, Japan
}

(Received August 19, 2016; Accepted February 13, 2017)

\begin{abstract}
Monoecious cucumber (Cucumis sativus L.) produces male and female flowers on the same plant, but application of ethylene promotes expression of female flowers. In the early bisexual stage, all flower buds contain primordia for both stamens and pistils and sexual differences are established by the selective arrest of sexual organ primordia. The expression of six cell cycle-related genes [Cs Cyclin A (CsCycA), CsCycB, CsCycD3; 1, CsCycD3; 2, Cs Cyclin-dependent kinase A (CsCDKA), and $C s C D K B]$ was analyzed in male and female flower buds to investigate cell cycle activity in sexual organs. CsCycA was expressed specifically in the area containing arrested stamen primordia (ACASP) in female flower buds, but was barely detected in male flower buds. Expression of the other five genes was detected in the ACASP but not in pistils of female flower buds. Expression of all six genes was elevated transiently following the application of 2chloroethylphosphonic acid (ethephon), an ethylene-releasing agent, to the shoot apices. The correlation of expression of these genes with the formation of female flowers suggests they play a role in the arrest of stamens of female flowers in monoecious cucumber plants.
\end{abstract}

Keywords : area containing arrested pistil primordia (ACAPP), area containing arrested stamen primordia (ACASP), arrested stamen primordia (ASP), cyclin, ethephon

\section{INTRODUCTION}

Cucumber (Cucumis sativus L.) has been used as a model higher plant for the study of sex expression (Galun, 1961; Shifriss, 1961; Kubicki, 1969a; 1969b; Malepszy and Niemirowicz-Szczytt, 1991). Sex expression in cucumber plants is genetically controlled by the $F$ and $M$ genes. These genes interact to produce four different sex phenotypes: gynoecious $(M-F-)$, monoecious ( $M-f f)$, hermaphroditic $(m m F-)$, and andromonoecious (mmff). Gynoecious cucumber plants produce only female flowers; monoecious plants produce both male and female flowers; hermaphroditic plants produce bisexual flowers with both staminate and pistillate organs; and andromonoecious plants produce bisexual and male flowers. Of these various sex phenotypes, monoecious is the most common type of sex expression in cucumber plants.

Morphologically, all flower buds in monoecious cucumber plants contain both stamen and pistil primordia at the early stage of their differentiation, and later develop into male or female flowers. Pistil development is arrested in flower buds destined to become male flowers, whereas stamen development is arrested in flower buds that become female flowers (Kubicki, 1969c; Yamasaki et al., 2005). Sex differences are thus established by the selective arrest of sexual organ primordia in monoecious cucumber plants.
In cucumber, sex expression can be regulated not only by the genetic loci described above, but also by plant hormones and environmental conditions (Atsmon and Galun, 1960; Shifriss and George, 1964; Frankel and Galun, 1977; Takahashi et al., 1983; Durand and Durand, 1984). In particular, production of the plant hormone ethylene is highly correlated with femaleness in cucumber plants, for example, gynoecious cucumber plants produce more ethylene than monoecious plants (George, 1971; Rudich et al., 1972; Trebitsh et al., 1987). In addition, inhibitors of ethylene biosynthesis or ethylene action suppress the development of female flowers and induce male flowers (Beyer, 1976; Atsmon and Tabbak, 1979; Takahashi and Suge, 1980; Takahashi and Jaffe, 1984; Yamasaki et al., 2000; Yamasaki and Manabe, 2011). Furthermore, application of ethylene to monoecious cucumber plants promotes the formation of female flowers (MacMurray and Miller, 1968; Iwahori et al., 1970; Takahashi and Suge, 1980; 1982; Yamasaki et al., 2000). These physiological phenomena were confirmed at the molecular level. Two genes (CS$A C S 1 G$ and $C S$-ACS2) which encode a key enzyme in the ethylene biosynthesis pathway, 1-aminocyclopropane-1carboxylic acid (ACC) synthase, were identified as being related to sex expression in cucumber plants. The $C S$ $A C S 1 G$ gene, which exists in gynoecious cucumber plants but not in monoecious cucumber plants, was closely linked to the $F$ gene (Trebitsh et al., 1997). The CS-ACS2 gene

Corresponding author: Seiji Yamasaki, fax: 81-940-35-1716, e-mail : yamasaki@fukuoka-edu.ac.jp 
was first isolated by Kamachi et al. (1997), who demonstrated that the expression of the CS-ACS2 gene coincides with development of female flowers in monoecious and gynoecious cucumber plants. Recently, the CS-ACS2 gene was identified as the $M$ gene (Boualem et al., 2009; Li et al., 2009). Thus, both $F$ and $M$ genes encode ACC synthase and ethylene is considered a sex hormone in $\mathrm{cu}-$ cumber plants.

Plant growth is driven by the process of cell division, coupled with subsequent cellular elongation and differentiation (Beemster et al., 2003; Jakoby and Schnittger, 2004). Cell division plays a role both in the developmental processes that create plant architecture and in the modulation of plant growth rates in response to the environment (Cockcroft et al., 2000; Beemster et al., 2002; De Veylder et al., 2011; Polyn et al., 2015). The mitotic cell cycle is characterized by a round of DNA replication (S phase) followed by mitosis and cytokinesis ( $\mathrm{M}$ phase), which are separated by two gap phases $\left(\mathrm{G}_{1}\right.$ and $\left.\mathrm{G}_{2}\right)$ (Inzé, 2005). Cyclin-dependent kinases (CDKs) and their cyclin partners regulate the $G_{1} / S$ and $G_{2} / M$ phase transitions as well as progression through, and exit from, the mitotic cell cycle (Menges et al., 2002; Beemster et al., 2005; Inzé and De Veylder, 2006; Berckmans and De Veylder, 2009; Harashima et al., 2013).

In higher plants, six distinct classes of CDKs, CDKA to CDKF, have been identified (Vandepoele et al., 2002). CDKA has been suggested to be an orthologue of yeast $\mathrm{Cdc} 2 / \mathrm{Cdc} 28 \mathrm{p}$ and a regulator of $\mathrm{G}_{1} / \mathrm{S}$ and $\mathrm{G}_{2} / \mathrm{M}$ phase progression (Magyar et al., 1997). CDKA; 1 is the sole gene encoding CDKA in Arabidopsis and it is expressed throughout the mitotic cell cycle (Vandepoele et al., 2002; Menges et al., 2005). Similarly, the expression and translation pattern of CDKA is constitutive during the mitotic cell cycle in tomato (Joubès et al., 2000). CDKBs are plantspecific CDKs whose expression is restricted to $G_{2} / M$ phase (Porceddu et al., 2001); therefore, CDKBs play a specific role in the regulation of the $G_{2} / M$ phase transition. Of the cyclin classes identified to date, the A- and B-type cyclins accumulate during the $G_{2}$ and early $M$ phases; Atype cyclins also accumulate during the $\mathrm{S}$ phase of the mitotic cell cycle (Mironov et al., 1999). D-type cyclins, also known as $\mathrm{G}_{1}$ proteins, control the progression through the $\mathrm{G}_{1}$ phase in response to environmental factors and nutrients, and therefore act as key regulators of entry into the mitotic cell cycle (Fuerst et al., 1996; Gutierrez et al., 2002; Shen, 2002; Trimarchi and Lees, 2002). Thus, agents regulating the mitotic cell cycle have been identified.

Although it is clear that ethylene regulates sex expression, the mechanism by which ethylene signals affect sexual organs, namely, the downstream mechanism of ethylene signaling during sex expression, remains unclear in monoecious cucumber plants. Given that sex differences are established by the selective arrest of sexual organ primordia, activity of the mitotic cell cycle must be affected during sex expression in such plants. Analyzing the expression of cell cycle-related genes in male and female flower buds of monoecious cucumber plants should help elucidate the roles of the mitotic cell cycle on sex differen- tiation at the molecular level. We analyzed the expression of six cell cycle-related genes [Cs Cyclin A ( CsCycA), CsCycB, CsCycD3; 1, CsCycD3; 2, Cs Cyclin-dependent kinase $A(C s C D K A)$, and $C s C D K B]$, previously isolated from cucumber (Fu et al., 2008; Zhang et al., 2009), in male and female flower buds of monoecious cucumber plants using semi-quantitative reverse transcription polymerase chain reaction (RT-PCR). We also analyzed expression of these genes in the shoot apices of plants treated with 2-chloroethylphosphonic acid (ethephon), an ethylene-releasing agent, using semi-quantitative RT-PCR. We discuss the roles of the activity of cell cycle in the sex expression of monoecious cucumber.

\section{MATERIALS AND METHODS}

\section{Plant materials}

A monoecious cucumber (Cucumis sativus L., 'Santosuyo No. 2') line was used in this study. Seeds were purchased from Nakahara Seed Co., Ltd., Fukuoka, Japan. Seeds were germinated on wet filter paper in a Petri dish and incubated at $26^{\circ} \mathrm{C}$ in the dark for 2 to $3 \mathrm{~d}$. Seedlings were then transferred to plastic pots containing a soil composite, Kumiai-Engei-Baido (0.4 g of N, $1.2 \mathrm{~g}$ of P, $0.2 \mathrm{~g}$ of K per kg; Seishin Sangyo Co., Kitakyushu, Japan). During the experiments, plants were provided with adequate water and supplied with fertilizer, $0.002 \%$ (v/v) Hyponex (Hyponex-Japan, Osaka, Japan). Plants were grown in a greenhouse at the University of Teacher Education Fukuoka under natural daylengths between mid-May and the end of July 2015.

Application of chemicals

To investigate the effect of ethylene on the expression of the six cell cycle-related genes $(C s C y c A, C s C y c B$, CsCycD3; 1, CsCycD3; 2, CsCDKA, and CsCDKB), $50 \mu \mathrm{l}$ of $0.35 \mathrm{mM}$ ethephon, an ethylene-releasing agent (Iwahori et al., 1970), in $\mathrm{H}_{2} \mathrm{O}$ containing $0.1 \%$ (v/v) Tween 20 was applied to the shoot apices of monoecious cucumber plants at the four-leaf stage (i.e., when the leaf blade of the fourth leaf was approximately $2 \mathrm{~cm}$ long) using a micropipette once a day for $3 \mathrm{~d}$. This treatment induced the formation of female flowers in monoecious cucumber plants (Yamasaki et al., 2000). Each replicate contained ten cucumber plants. The shoot apices were cut using a razor blade $0.5,6$, and 24 $\mathrm{h}$ post-ethephon application for $3 \mathrm{~d}$. The samples were frozen immediately in liquid nitrogen and stored at $-80^{\circ} \mathrm{C}$ prior to the extraction of nucleic acids.

Semi-quantitative RT-PCR analysis

Male and female flower buds were classified from stage I to III based on the development state, as described in Table 1. Sexuality of the flowers could be determined by stage I due to the presence of an ovary. In male flowers, the area containing arrested pistil primordia (ACAPP) (Fig. $1 \mathrm{~A}$ ) is left after removing sepals, petals, and stamens. In female flowers, the area containing arrested stamen primordia (ACASP) (Fig. 1B) is left after removing sepals, petals, and pistils. Male flower buds at stage I were dissected into four floral organs (sepals, petals, stamens, and ACAPP) using a forceps and scalpel under a stereomicro- 
EXPRESSION OF CELL CYCLE GENES

Table 1 Developmental stages of male and female flower buds of cucumber, classified in accordance with a previous report (Yamasaki and Manabe, 2009).

\begin{tabular}{lcc}
\hline & Length of flower buds $(\mathrm{mm})$ & Morphological characters \\
\hline Male flower buds & $3-5$ & \\
Stage I & $8-10$ & Mononuclear pollen formation \\
Stage II & $13-15$ & Pollen maturation \\
Stage III & & Anthesis (flower opening) \\
Female flower buds & $5-10$ & \\
Stage I & $20-25$ & Stigma and ovary development \\
Stage II & $35-40$ & Embryo sac maturation \\
Stage III & & Anthesis (flower opening) \\
\hline
\end{tabular}

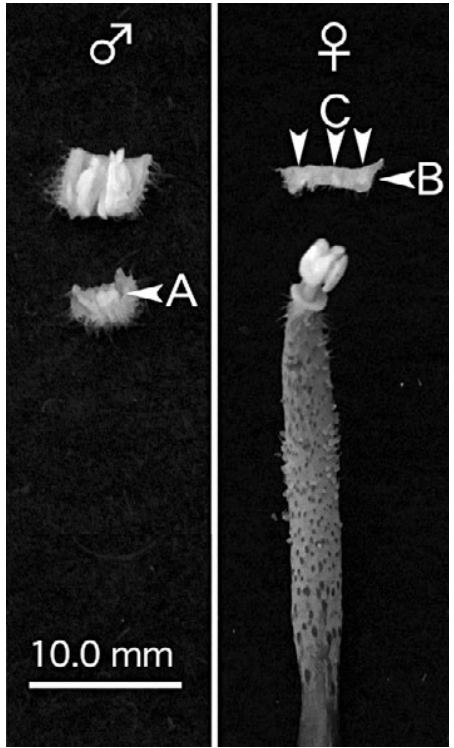

Fig. 1 Dissected male and female cucumber flowers at stage III. A. Area containing arrested pistil primordia (ACAPP) in male flowers. B. Area containing arrested stamen primordia (ACASP) in female flowers. C. Arrested stamen primordia (ASP) in female flowers.

scope (SPZT-50FTM; Carton Optical Industries, Ltd., Tokyo, Japan). Female flower buds at stage I were also dissected into four floral organs (sepals, petals, ACASP, and pistils). These samples were frozen immediately in liquid nitrogen and stored at $-80^{\circ} \mathrm{C}$ prior to the extraction of nucleic acids.

Total RNA was extracted from male and female flower buds at stage I, from the individual floral organs (sepals, petals, stamens, and ACAPP) of male flower buds at stage I, from the individual floral organs (sepals, petals, ACASP, and pistils) of female flower buds at stage I, and from shoot apices treated with ethephon, using TRI reagent (Sigma-Aldrich Co., Tokyo, Japan), according to the manufacturer's instructions. The concentration of total RNA was measured using spectrophotometry (V-630BIO; Jasco Co., Tokyo, Japan). cDNA was synthesized from total RNA using Rever Tra Ace ${ }^{\circledR}$ (Toyobo Co., Ltd., Osaka, Japan) and random hexamers in a $20 \mu \mathrm{l}$ reaction volume. PCR was performed using Premix Taq (TaKaRa Ex Taq $^{\mathrm{TM}}$ Version, Takara Shuzo Co., Ltd., Shiga, Japan), $1 \mu \mathrm{l}$ of cDNA, and gene-specific primers.

The following gene-specific primers were used: for CsCycA (accession number: EW968279), CsCycA-F2 5'-
TCG AAA TGA CAG CTC CAA CA-3' and CsCycA-R2 5'-TGC TGG CTG TAT TTT TCT CTG A-3'; for $C s C y c B$ (accession number: EW968280), CsCycB-F2 5'-AAG AAG CTG AGA ACG AGA GCA-3' and CsCycB-R 5'TAC CAC TCC AAC TTC CCA AG-3'; for $C s C y c D 3 ; 1$ (accession number: EW968283), CsCycD3: 1-F2 5'-TCT GTT TTG GCA ACT GCA AC-3' and CsCycD3: 1-R3 5'CTG AAC TGA AAC CTG CGT CA-3'; for CsCycD3; 2 (accession number: EW968284), CsCycD3:2-F 5'-CAG AGA ATG GAG CTT TTG GTT C-3' and CsCycD3: 2-R 5'-ACA CAA TCG TCC CCA TAT CC-3'; for CsCDKA (accession number: EW968281), CsCDKA-F2 5'-TGT TGA AGG AAA TGC AGC AC-3' and CsCDKA-R2 5'TCA TTT CGG CAA ATA TGC AA- $3^{\prime}$; for CsCDKB (accession number: EW968282), CsCDKB-F3 5'-CAA TCC CTC TAT GTC GTT CG-3' and CsCDKB-R2 5'-GCT TGA GAT CAC GGT GAA GA-3'; and for $C s$ Glyceraldehyde-3-phosphate dehydrogenase (CsGAPDH) (accession number: HQ156465), CsGAP-F 5'-TGG TGA GAA GGC TGT CAC TG-3' and CsGAP-R2 5'-TGG TCA TCA GAC CCT CAA CA-3'.

The PCR conditions were $94^{\circ} \mathrm{C}$ for $30 \mathrm{~s}, 55^{\circ} \mathrm{C}$ for 1 min, and $72^{\circ} \mathrm{C}$ for $1 \mathrm{~min}$. The PCR products were separated using electrophoresis on a $2.0 \%$ agarose gel and stained with ethidium bromide $\left(0.5 \mu \mathrm{g} \mathrm{ml}^{-1}\right)$ for $40 \mathrm{~min}$. The gel was washed in distilled water for 5 min and photographed on a UV transilluminator (M-15, Funakoshi Co., Ltd., Tokyo, Japan). The intensity of the bands was measured using the public-domain NIH Image program (http: //rsb.Info.nih.gov/nih-image/, November 25, 2015). CsGAPDH was used as an internal control, and the expression levels of cell cycle-related genes were evaluated according to the ratio of the density of cell cycle-related genes/CsGAPDH.

Before performing semi-quantitative RT-PCR analysis, the number of cycles for each gene amplification was determined from the titration curves of the corresponding RT-PCR products. The signal intensities of the RT-PCR products were expressed in arbitrary units and plotted against cycle numbers (data not shown).

Analysis of epidermal cell number at stamens compared to petals in male and female flower buds

To investigate epidermal cell number in stamens compared to petals in male flower buds, petals and stamens were dissected from male flower buds at stage II using a forceps and scalpel under a stereomicroscope. Similarly, in female flower buds, petals and the ACASP were dissected 
from female flower buds at stage II. These samples were immersed in 50\% (v/v) bleach (Kitchen Kirei kirei Jokin and Hyohaku; Lion Co., Tokyo, Japan) until they were decolorized. After washing with distilled water, they were observed using a stereomicroscope or light microscope (ECLIPSE E600W; Nikon, Co., Tokyo, Japan). Epidermal cell area was calculated using photomeasure software (Kenis Ltd., Osaka, Japan) $(n=30)$. Epidermal cell number per $\mathrm{mm}^{2}$ was estimated through dividing $1.0 \mathrm{~mm}^{2}$ by the mean area of 30 epidermal cells. This analysis was performed separately on three male flower and three female flower buds.

\section{RESULTS AND DISCUSSION}

To investigate how cell cycle activity of sexual organs correlated with sex expression, the expression of six cell cycle-related genes ( $C s C y c A, C s C y c B, C s C y c D 3 ; 1$, $C s C y c D 3 ; 2, C s C D K A$, and $C s C D K B$ ) was analyzed in male and female flower buds at stage I from monoecious cucumber plants. Expression of $C s C y c A$ was not detected in four floral organs from male flower buds, whereas it was detected in female flower buds, mainly in the ACASP (Fig. 2A, B). Indeed, expression of $C s C y c A$ was detected in female flower buds but not in male flower buds at stage I (Fig. 2C). Expression of $C s C y c B$ was detected in all four floral organs in male flower buds (Fig. 2A), but, in female flower buds, $C s C y c B$ expression occurred mainly in the ACASP (Fig. 2B). CsCycD3; 1 expression was seen mainly in the petals of male flower buds (Fig. 2A) but in the sepals, petals, and the ACASP in female flower buds (Fig. 2B). CsCycD3; 2 expression was detected mainly in the stamens of male flower buds (Fig. 2A), in contrast to the petals and the ACASP in female flower buds (Fig. 2B). Expression of $C s C D K A$ was observed mainly in petals and the ACAPP in male flower buds (Fig. 2A), but CsCDKA expression was seen in female flower buds in the sepals and in the ACASP (Fig. 2B). Expression of $C s C D K B$ was detected mainly in sepals, petals, and stamens, with low expression in the ACAPP, of male flower buds (Fig. 2A), whereas, in female flower buds, it was detected in sepals, petals, and the ACASP (Fig. 2B). In summary, of the six genes, $C s C y c A$ showed specific expression in the ACASP in the female flower buds of monoecious cucumber plants. Expression of the other five genes $(C s C y c B, C s C y c D 3 ; 1$, $C s C y c D 3 ; 2, C s C D K A$, and $C s C D K B$ ) in female flower buds occurred in the ACASP but was barely detectable in

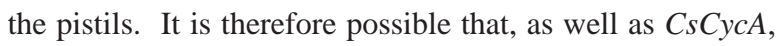
these five genes are involved in the arrest of stamen primordia in female flower buds of monoecious cucumber plants. In male flower buds, expression of $C s C y c B$, $C s C y c D 3 ; 2$, and $C s C D K B$ genes was detected in stamens and expression of $C s C y c B, C s C D K A$, and $C s C D K B$ genes was detected in the ACAPP. Thus, it is possible that $C s C y c B, C s C y c D 3 ; 2$, and $C s C D K B$ genes are involved in the development of stamens and $C s C y c B, C s C D K A$, and $C s C D K B$ genes are involved in the arrest of pistil primordia.

Application of ethylene to monoecious cucumber
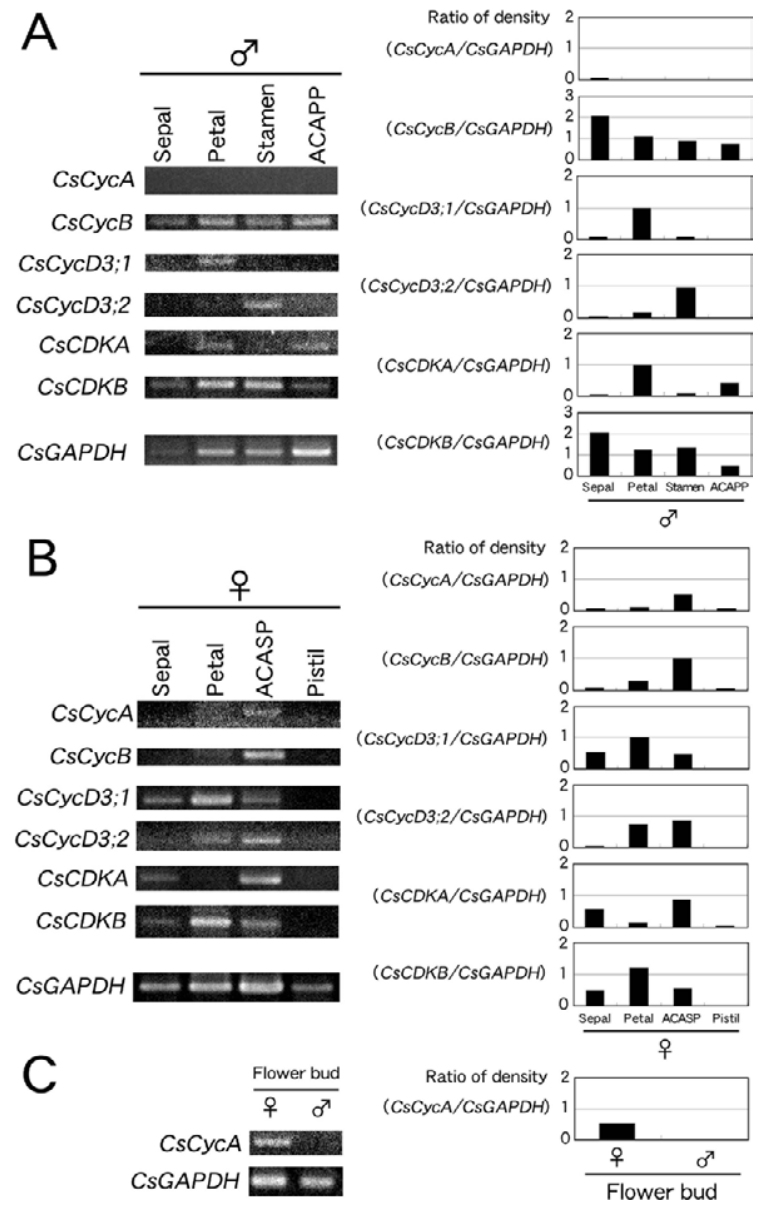

Fig. 2 Semi-quantitative RT-PCR analysis of expression of cell cycle-related genes in male and female cucumber flower buds. A. mRNA levels of six cell cycle-related genes ( $C s C y c A, C s C y c B, C s C y c D 3 ; 1, C s C y c D 3 ; 2$, $C s C D K A$, and $C s C D K B$ ) in four floral organs (sepals, petals, stamens, and ACAPP) from male flower buds at stage I. The ratio of the density of each cell cyclerelated gene to a reference gene $(C s G A P D H)$ is shown. B. mRNA levels of six cell cycle-related genes (CsCycA, CsCycB, CsCycD3; 1, CsCycD3; 2, $C s C D K A$, and $C s C D K B$ ) in four floral organs (sepals, petals, ACASP, and pistils) of female flower buds at stage I. The ratio of the density of each cell cyclerelated gene to a reference gene $(C s G A P D H)$ is shown. C. mRNA levels of $C s C y c A$ in male and female flower buds at stage I. The ratio of the density of $C s C y c A / C s G A P D H$ is shown.

plants promotes the formation of female flowers (MacMurray and Miller, 1968; Iwahori et al., 1970; Takahashi and Suge, 1980; 1982; Yamasaki et al., 2000). To investigate the relationship between expression of the six cell cycle-related genes and formation of female flowers, we analyzed the effect of ethephon, an ethylenereleasing agent, on the expression of these genes.

Expression of the six genes was upregulated between 1.7- and 5.3-fold following ethephon treatment for $6 \mathrm{~h}$ (Fig. 3). Expression of $\operatorname{CsCycA}$ was upregulated 4.9-fold following ethephon treatment for $0.5 \mathrm{~h}$ (Fig. 3). Expression of $C s C y c B$ was upregulated 2.4- and 1.7-fold following ethephon treatment for 0.5 and $24 \mathrm{~h}$, respectively (Fig. 3). Expression of $C s C D K B$ increased 2.7-fold following 


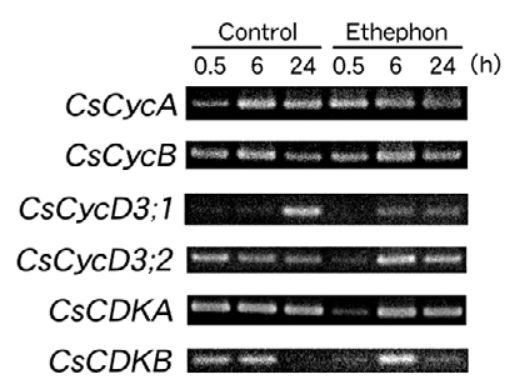

CSGAPDH man

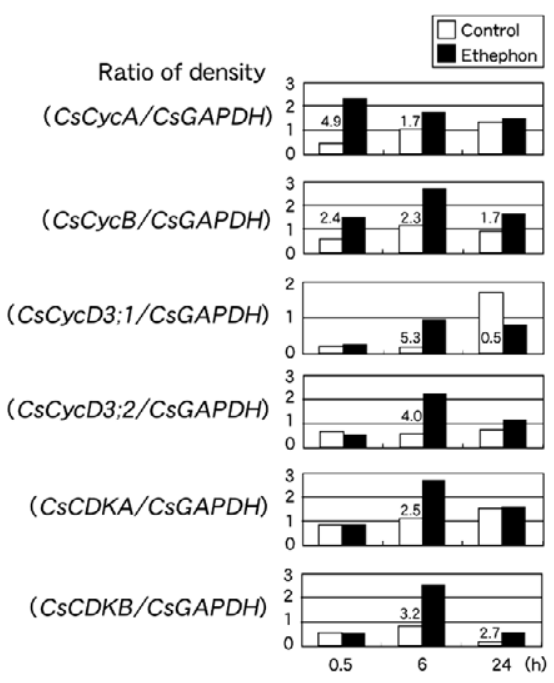

Fig. 3 The effects of application of ethephon on expression of cell cycle-related genes (CsCycA, CsCycB, CsCycD3; 1, CsCycD3;2, CsCDKA, and $C s C D K B$ ) in the shoot apices of monoecious cucumber plants at the four-leaf stage (left-hand side). The ratio of the signal densities of each cell cycle-related gene to a control gene CsGAPDH is shown (right-hand side). The inset numbers in the graph on the right-hand side of the figure are the ratios of the signal densities of each cell cycle-related gene between ethephontreated plants and control plants.

ethephon treatment for $24 \mathrm{~h}$ (Fig. 3). By contrast, CsCycD3; 1 expression decreased by half following ethephon treatment for $24 \mathrm{~h}$ (Fig. 3). In summary, expression of all six genes was upregulated within $6 \mathrm{~h}$ of ethephon treatment, with expression of $C s C y c A$ and $C s C y c B$ being upregulated especially fast (within $0.5 \mathrm{~h}$ of ethephon treatment). This suggests that these six cell cycle-related genes are involved in the formation of female flowers in monoecious cucumber plants.

Analysis of gene expression suggested that, at a molecular level, cell cycle activity was high in the ACASP in female flower buds of monoecious cucumber plants (Figs. $2,3)$. In this case, the epidermal cell number in arrested stamen primordia (ASP) (Fig. 1C), compared with other organs, should increase in a later developmental stage of female flower buds. To test this hypothesis, the epidermal cell size and number in stamens and ASP was compared with that in another organ, the petals, in male and female flower buds at stage II.

In male flower buds at stage II, stamens were well developed (Fig. 4A, B; white and black arrowheads). Epidermal cell size in stamens (Fig. 4C; black arrowhead) did not differ significantly from that in petals (Fig. 4D; black arrowhead) in male flower buds. Stamen primordia were arrested in female flower buds at stage II (Fig. 4E, F; white and black arrowheads). Epidermal cells in ASP (Fig. $4 \mathrm{G}$; black arrowhead) were smaller than those in petals (Fig. 4H; black arrowhead) in female flower buds.

The sizes of epidermal cells in petals and stamens (or ASP) in male and female flower buds were used to calculate the number of epidermal cells per $\mathrm{mm}^{2}$ of tissue. In male flower buds, the epidermal cell number per $\mathrm{mm}^{2}$ did not differ significantly between petals and stamens (Fig. 5); however, in female flower buds, the epidermal cell number per $\mathrm{mm}^{2}$ in the ASP was much greater than that in petals (Fig. 5). As the epidermal cell number per unit area in ASP was greater in female flower buds, the hypothesis was supported. These results strongly support the conclusion that, at the cellular level, cell division is maintained at a high rate in the ACASP in female flower buds. In general, cell division rates are high in places where cells are actively generated, such as the shoot and root apical meristems in higher plants (Grandjean et al., 2004; McCulloch and Till, 2005; Scheres, 2007; Morrison and Spradling, 2008). To our knowledge, these results are the first evidence that cell division is maintained at a high level in arrested tissue in higher plants. The comparison of cell sizes between ASP in female flower buds and developed stamens in male flowers (Fig. 4C, G) indicated that cell growth was restrained at ASP in female flower buds. Thus, the condition of the cells at ASP in female flower buds of monoecious cucumber plants was estimated as follows: although cell division rates remained high, cell growth was restrained.

In monoecious plants, the process of sex differentiation often involves cell death, resulting in the selective abortion of either stamen or pistil primordia ( $\mathrm{Wu}$ and Cheung, 2000). Hao et al. (2003) demonstrated in cucumber that the arrest of stamen primordia involves programmed cell death (PCD) in female flowers; however, Bai et al. (2004) concluded that PCD might not be involved in the arrest of pistil primordia in male flowers. Isolation of the gene Cs1-matrix metalloproteinase (MMP) in cucumber showed its expression is involved in triggering or regulating PCD in cotyledons (Delorme et al., 2000). MMPs are a major group of enzymes that degrade the extracellular cell matrix (ECM) and are thought to play an important role in pathological processes such as arthritis, cancer and fibrotic diseases in animals (Woessner, 1998). We previously showed strong Cs 1-MMP expression in the ACASP in female flower buds at stage I-III and in the ACAPP in male flower buds at stage I-III of monoecious cucumber plants (Yamasaki and Manabe, 2009). Such studies 

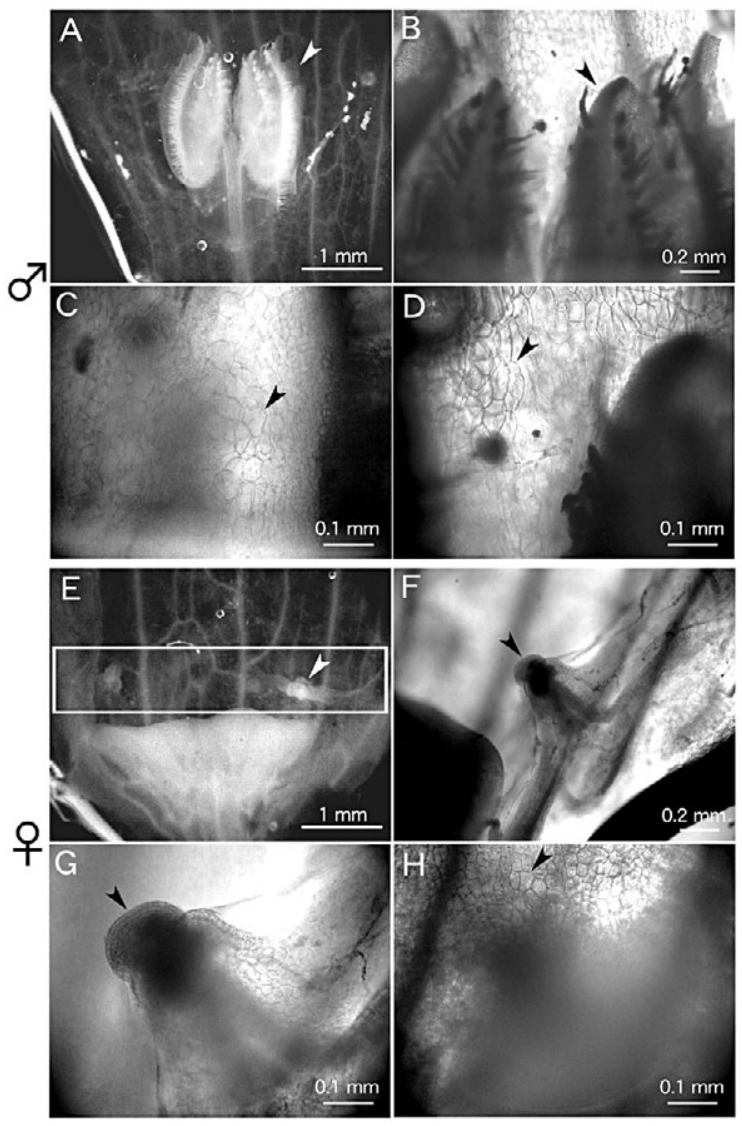

Fig. 4 Cell sizes in monoecious cucumber flower buds. A, B. Developed stamens (white and black arrowheads) of male flower buds at stage II. C. Epidermal cells (black arrowhead) in developed stamens of male flower buds at stage II. D. Epidermal cells (black arrowhead) in petals of male flower buds at stage II. E, F. ASP (white and black arrowheads) in female flower buds at stage II. White square in figure $\mathrm{E}$ shows ACASP. G. Epidermal cells (black arrowhead) in ASP of female flower buds at stage II. H. Epidermal cells (black arrowhead) in petals of female flower buds at stage II.

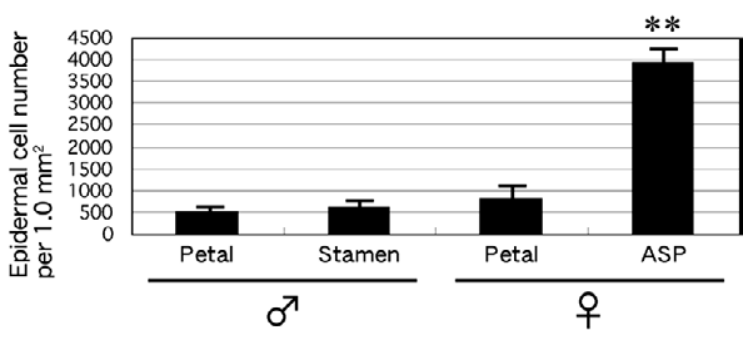

Fig. 5 Epidermal cell number per $\mathrm{mm}^{2}$ in petals and stamens of male flower buds and in petals and ASP of female flower buds at stage II. Values represent the average of 90 epidermal cells from three flower buds \pm standard error. Statistically significant differences were determined using the Student's $t$-test (**: $P<0.01$ vs. petals).

indicate that PCD is involved in the arrest of stamen primordia in female flower buds of monoecious cucumber plants. Taken together with the results of the current study, it appears that cells under division, restrained growth, and death coexist in the ASP in female flower buds of monoecious cucumber plants. The following scenario is likely: although cell division activity is maintained at a high rate, cell growth is restrained and, finally, PCD occurs at ASP in female flower buds of monoecious cucumber plants. To understand the precise mechanism of sex differences in monoecious cucumber, it will be necessary to clarify the mutual relationships between cell division activity, restrained cell growth, and PCD in the future.

\section{ACKNOWLEDGMENTS}

This work was partially supported by the Japan Society for the Promotion of Science, a Grant-in-Aid for Scientific Research (C) (no. 15K07292 to S.Y.), the 5th Nissan Science Foundation, and the Saito Gratitude Foundation.

\section{REFERENCES}

Atsmon, D., Galun, E. 1960. A morphogenetic study of staminate, pistillate and hermaphrodite flowers in Cucumis sativus L. Phytomorphology 10: 110-115.

Atsmon, D., Tabbak, C. 1979. Comparative effects of gibberellin, silver nitrate and aminoethoxyvinyl glycine on sexual tendency and ethylene evolution in the cucumber plant (Cucumis sativus L.). Plant Cell Physiol. 20: 1547-1555.

Bai, S. L., Peng, Y. B., Cui, J. X., Gu, H. T., Xu, L. Y., Li, Y. Q., Xu, Z. H., Bai, S. N. 2004. Developmental analyses reveal early arrests of the spore-bearing parts of reproductive organs in unisexual flowers of cucumber (Cucumis sativus L.). Planta 220: $230-240$

Beemster, G. T. S., De Veylder, L., Vercruysse, S., West, G., Rombaut, D., Hummelen, P. V., Galichet, A., Gruissem, W., Inzé, D., Vuylsteke, M. 2005. Genome-wide analysis of gene expression profiles associated with cell cycle transitions in growing organs of Arabidopsis. Plant Physiol. 138: 734743.

Beemster, G. T. S., De Vusser, K., De Tavernier, E., De Bock, K., Inzé, D. 2002. Variation in growth rate between Arabidopsis ecotypes is correlated with cell division and Atype cyclin-dependent kinase activity. Plant Physiol. 129: 854-864.

Beemster, G. T. S., Fiorani, F., Inzé, D. 2003. Cell cycle: the key to plant growth control? Trends Plant Sci. 8: 154-158.

Berckmans, B., De Veylder, L. 2009. Transcriptional control of the cell cycle. Curr. Opin. Plant Biol. 12: 599-605.

Beyer, E. M. 1976. Silver ion: A potent antiethylene agent in cucumber and tomato. HortScience 11: 195-196.

Boualem, A., Troadec, C., Kovalski, I., Sari, M. A., Treves, R. P., Bendahmane, A. 2009. A conserved ethylene biosynthesis enzyme leads to andromonoecy in two cucumis species. PloS ONE 4: e6144.

Cockcroft, C. E., Den Boer, B. G. W., Healy, J. M. S., Murray, J. A. H. 2000. Cyclin D control of growth rate in plants. Nature 405: 575-579.

Delorme, V. G. R., McCabe, P. F., Kim, D. J., Leaver, C. J. 2000. A matrix metalloproteinase gene is expressed at the boundary of senescence and programmed cell death in cucumber. Plant Physiol. 123: 917-927.

De Veylder, L., Larkin, J. C., Schnittger, A. 2011. Molecular control and function of endoreplication in development and physiology. Trends Plant Sci. 16: 624-634.

Durand, R., Durand, B. 1984. Sexual differentiation in higher plants. Physiol. Plant. 60: 267-274.

Frankel, R., Galun, E. 1977. Pollination Mechanisms, 


\section{EXPRESSION OF CELL CYCLE GENES}

Reproduction, and Plant Breeding. Springer-Verlag, Berlin Heidelberg, New York.

Fu, F. Q., Mao, W. H., Shi, K., Zhou, Y. H., Asami, T., Yu, J. Q. 2008. A role of brassinosteroids in early fruit development in cucumber. J. Exp. Bot. 59: 2299-2308.

Fuerst, R. A. U. A., Soni, R., Murray, J. A. H., Lindsey, K. 1996. Modulation of cyclin transcript levels in cultured cells of Arabidopsis thaliana. Plant Physiol. 112: 1023-1033.

Galun, E. 1961. Study of the inheritance of sex expression in the cucumber: The interaction of major genes with modifying genetic and non-genetic factors. Genetica 32: 134-163.

George, W. L. 1971. Influence of genetic background on sex conversion by 2-chloroethylphosphonic acid in monoecious cucumbers. J. Am. Soc. Hortic. Sci. 96: 152-154.

Grandjean, O., Vernoux, T., Laufs, P., Belcram, K., Mizukami, Y., Traas, J. 2004. In vivo analysis of cell division, cell growth, and differentiation at the shoot apical meristem in Arabidopsis. Plant Cell 16: 74-87.

Gutierrez, C., Ramirez-Parra, E., Castellano, M. M., del Pozo, J. C. 2002. $\mathrm{G}(1)$ to $\mathrm{S}$ transition: more than a cell cycle engine switch. Curr. Opin. Plant Biol. 5: 480-486.

Hao, Y. J., Wang, D. H., Peng, Y. B., Bai, S. L., Xu, L. Y., Li, Y. Q., Xu, Z. H., Bai, S. N. 2003. DNA damage in the early primordial anther is closely correlated with stamen arrest in the female flower of cucumber (Cucumis sativus L.). Planta 217: 888-895.

Harashima, H., Dissmeyer, N., Schnittger, A. 2013. Cell cycle control across the eukaryotic kingdom. Trends Cell Biol. 23: 345-356.

Inzé, D. 2005. Green light for the cell cycle. EMBO J. 24: 657662.

Inzé, D., De Veylder, L. 2006. Cell cycle regulation in plant development. Ann. Rev. Genet. 40: 77-105.

Iwahori, S., Lyons, J. M., Smith, O. E. 1970. Sex expression in cucumber plants as affected by 2-chloroethylphosphonic acid, ethylene, and growth regulators. Plant Physiol. 46: 412-415.

Jakoby, M., Schnittger, A. 2004. Cell cycle and differentiation. Curr. Opin. Plant Biol. 7: 661-669.

Joubès, J., Walsh, D., Raymond, P., Chevalier, C. 2000. Molecular characterization of the expression of distinct classes of cyclins during the early development of tomato fruit. Planta 211: 430-439.

Kamachi, S., Sekimoto, H., Kondo, N., Sakai, S. 1997. Cloning of a cDNA for a 1-aminocyclopropane-1-carboxylate synthase that is expressed during development of female flowers at the apices of Cucumis sativus L. Plant Cell Physiol. 38: 11971206.

Kubicki, B. 1969a. Investigations on sex determination in cucumbers (Cucumis sativus L.). V. Genes controlling intensity of femaleness. Genet. Pol. 10: 69-85.

Kubicki, B. 1969b. Investigations on sex determination in cucumber (Cucumis sativus L.). VI. Androecism Genet. Pol. 10: $87-98$.

Kubicki, B. 1969c. Investigations on sex determination in cucumbers (Cucumis sativus L.). VIII. Trimonoecism Genet. Pol. 10: 123-143.

Li, Z., Huang, S., Liu, S., Pan, J., Zhang, Z., Tao, Q., Shi, Q., Jia, Z., Zhang, W., Chen, H., Si, L., Zhu, L., Cai, R. 2009. Molecular isolation of the $M$ gene suggests that a conservedresidue conversion induces the formation of bisexual flowers in cucumber plants. Genetics 182: 1381-1385.

MacMurray, A. L., Miller, C. M. 1968. Cucumber sex expression modified by 2-chloroethanephosphonic acid. Science 162: 1397-1398.

Magyar, Z., Mészáros, T., Miskolczi, P., Deák, M., Fehér, A., Brown, S., Kondorosi, E., Athanasiadis, A., Pongor, S.,
Bilgin, M., Bakó, L., Koncz, C., Dudits, D. 1997. Cell cycle phase specificity of putative cyclin-dependent kinase variants in synchronized alfalfa cells. Plant Cell 9: 223-235.

Malepszy, S., Niemirowicz-Szczytt, K. 1991. Sex determination in cucumber (Cucumis sativus L.) as a model system for molecular biology. Plant Sci. 80: 39-47.

McCulloch, E. A., Till, J. E. 2005. Perspectives on the properties of stem-cells. Nat. Med. 11: 1026-1028.

Menges, M., De Jager, S. M., Gruissem, W., Murray, J. A. 2005. Global analysis of the core cell cycle regulators of Arabidopsis identifies novel genes, reveals multiple and highly specific profiles of expression and provides a coherent model for plant cell cycle control. Plant J. 41: 546-566.

Menges, M., Hennig, L., Gruissem, W., Murray, J. A. H. 2002. Cell cycle-regulated gene expression in Arabidopsis. J. Biol. Chem. 277: 41987-42002.

Mironov, V., De Veylder, L., Van Montagu, M., Inzé, D. 1999. Cyclin-dependent kinases and cell division in plants - the nexus. Plant Cell 11: 509-521.

Morrison, S. J., Spradling, A. 2008. Stem cells and niches: Mechanisms that promote stem cell maintenance throughout life. Cell 132: 598-611.

Polyn, S., Willems, A., De Veylder, L. 2015. Cell cycle entry, maintenance, and exit during plant development. Curr. Opin. Plant Biol. 23: 1-7.

Porceddu, A., Stals, H., Reichheld, J. P., Segers, G., De Veylder, L., Barrôco, R. P., Casteels, P., Van Montagu, M., Inzé, D., Mironov, V. 2001. A plant-specific cyclin-dependent kinase is involved in the control of $\mathrm{G}_{2} / \mathrm{M}$ progression in plants. J. Biol. Chem. 276: 36354-36360.

Rudich, J., Halevy, A. H., Kedar, N. 1972. Ethylene evolution from cucumber plants as related to sex expression. Plant Physiol. 49: 998-999.

Scheres, B. 2007. Stem-cell niches: nursery rhymes across kingdoms. Nat. Rev. Mol. Cell Biol. 8: 345-354.

Shen, W. H. 2002. The plant E2F-Rb pathway and epigenetic control. Trends Plant Sci. 7: 505-511.

Shifriss, O. 1961. Sex control in cucumbers. J. Hered. 52: 5-12.

Shifriss, O., George, W. L. Jr. 1964. Sensitivity of female inbreds of Cucumis sativus to sex reversion by gibberellin. Science 143: 1452-1453.

Takahashi, H., Jaffe, M. J. 1984. Further studies of auxin and ACC induced feminization in the cucumber plant using ethylene inhibitors. Phyton 44: 81-86.

Takahashi, H., Saito, T., Suge, H. 1983. Separation of the effects of photoperiod and hormones on sex expression in cucumber. Plant Cell Physiol. 24: 147-154.

Takahashi, H., Suge, H. 1980. Sex expression in cucumber plants as affected by mechanical stress. Plant Cell Physiol. 21: 303-310.

Takahashi, H., Suge, H. 1982. Sex expression and ethylene production in cucumber plants as affected by 1aminocyclopropane-1-carboxylic acid. J. Jpn. Soc. Hortic. Sci. 51: 51-55.

Trebitsh, T., Riov, J., Rudich, J. 1987. Auxin, biosynthesis of ethylene and sex expression in cucumber (Cucumis sativus). Plant Growth Regul. 5: 105-113.

Trebitsh, T., Staub, J. E., O'Neill, S. D. 1997. Identification of a 1-aminocyclopropane-1-carboxylic acid synthase gene linked to the female $(F)$ locus that enhances female sex expression in cucumber. Plant Physiol. 113: 987-995.

Trimarchi, J. M., Lees, J. A. 2002. Sibling rivalry in the E2F family. Nature Rev. Mol. Cell Biol. 3: 11-20.

Vandepoele, K., Raes, J., De Veylder, L., Rouzé, P., Rombauts, S., Inzé, D. 2002. Genome-wide analysis of core cell cycle genes in Arabidopsis. Plant Cell 14: 903-916. 


\section{S.YAMASAKI ET AL.}

Woessner, J. F. 1998. The matrix metalloproteinase family. In "Matrix Metalloproteinases" (ed. by Parks, W. C., Mecham, R. P.), Academic Press, San Diego, p 1-14.

Wu, H. M., Cheung, A. Y. 2000. Programmed cell death in plant reproduction. Plant Mol. Biol. 44: 267-281.

Yamasaki, S., Fujii, N., Takahashi, H. 2000. The ethyleneregulated expression of CS-ETR2 and CS-ERS genes in cucumber plants and their possible involvement with sex expression of flowers. Plant Cell Physiol. 41: 608-616.

Yamasaki, S., Fujii, N., Takahashi, H. 2005. Hormonal regulation of sex expression in plants. In "Vitamins and Hormones" (ed. By Litwack, G.), Vol. 72, Academic Press, San Diego, p 79-110.
Yamasaki, S., Manabe, K. 2009. Potential involvement of Cs1$M M P$ in the arrest of sex organ development during sexual experssion in cucumber (Cucumis sativus L.). J. Jpn. Soc. Hortic. Sci. 78: 195-199.

Yamasaki, S., Manabe, K. 2011. Application of silver nitrate induces functional bisexual flowers in gynoecious cucumber plants (Cucumis sativus L.). J. Jpn. Soc. Hortic. Sci. 80: 6675.

Zhang, Y., Gu, M., Xia, X., Shi, K., Zhou, Y., Yu, J. 2009. Effects of phenylcarboxylic acids on mitosis, endoreduplication and expression of cell cycle-related genes in roots of cucumber (Cucumis sativus L.). J. Chem. Ecol. 35: 679-688. 